\title{
ARTIGO
}

\section{A (in)aplicabilidade da qualificadora do feminicídio e da Lei Maria da Penha às mulheres transexuais}

\author{
Edson Jordan Mendes de Souza $a^{1}$ Francielle da Conceição Drumond Figueiredo ${ }^{2}$
}

Como citar este artigo: SOUZA, Edson Jordan Mendes de; FIGUEIREDO, Francielle da Conceição Drumond. A (in)aplicabilidade da qualificadora do feminicídio e da Lei Maria da Penha às mulheres transexuais. Revista de Ciências do Estado. Belo Horizonte: v. 6, n. 1, 2021.

Resumo: Este artigo tem por objetivo apresentar, em linhas gerais, o reconhecimento jurídico da possibilidade da aplicabilidade da qualificadora de feminicídio e da Lei Maria da Penha a mulheres transexuais. A transexualidade se refere à condição do indivíduo cuja identidade de gênero difere daquela designada no nascimento, e que procura fazer a transição para o gênero oposto através de intervenção médica, podendo ocorrer, ou não, a cirurgia de redesignação sexual, ou, apenas a feminilização/masculinização, dependendo do gênero a ser transicionado, por intermédio da administração de hormônios. As metodologias utilizadas para desenvolver o presente trabalho são a bibliográfica e a analítico-dogmática. Com a metodologia bibliográfica tem-se uma análise da literatura jurídica especializada e dedicada ao tema do reconhecimento dos direitos das pessoas transexuais. A investigação analítico-dogmática tem por objetivo analisar a legislação aplicável e interpretá-la de modo a viabilizar o máximo reconhecimento de novos direitos.

Palavras-chave: Transexualidade; Lei Maria da Penha; Feminicídio; Aplicabilidade.

\footnotetext{
${ }^{1}$ Acadêmico do $9^{\circ}$ período de Direito da Faculdade Vale do Gorutuba-FAVAG. Atuando principalmente nos seguintes temas: multiparentelidade, reconhecimento jurídico das pessoas LGBTQIA+, criminalização da LGBTfobia e a alteração do registro civil de pessoas transexuais e travestis. ORCID: https://orcid.org/00000002-6358-8484

${ }^{2}$ Mestre em Fundamentos e Efetividade do Direito pela UniFG, Pós Graduada em Análise da Criminalidade pela Unimontes, Pós Graduada em Inovação e Metodologias do Ensino Superior pela FAVAG, Delegada de Polícia no estado de Minas Gerais, professora universitária, com experiências nas àreas de Direito Penal e Processual Penal. ORCID: https://orcid.org/0000-0003-4130-8581
} 


\section{INTRODUÇÃO}

A mulher sempre foi inferiorizada na sociedade, sendo privada de direitos básicos e inerentes a pessoa humana, como por exemplo: o direito a educação, sendo um direito exclusivo ao gênero masculino, ou seja, ao provedor de sustento da casa. Deixando, assim, a mulher como mera cuidadora do lar e dos filhos, além de ser considerada como um objeto de satisfação do prazer masculino.

Essa situação de inferiorização do gênero feminino perdura até os tempos atuais. Levando em consideração a época em que a Lei Maria da Penha (Lei n ${ }^{\circ}$ 11.340/2006) foi promulgada, a mesma só foi editada após uma grande pressão dos órgãos máximos de direitos humanos mundiais.

A Lei Maria da Penha (Lei $\left.\mathrm{n}^{\circ} 11.340 / 2006\right)$ e a qualificadora do feminicídio (inciso VI do art. 121, $\S 2^{\circ}$, do Código Penal) são normas que visam proteger o bem estar físico e social da mulher, a partir de sua posição de fragilidade nas relações domésticas e sociais. Desta maneira fazendo prevalecer o princípio constitucional da equidade social: tratar os desiguais na medida de suas desigualdades.

As normas supra somente incidem nos casos que uma mulher configura o polo passivo do delito, entendidos como aqueles que envolvem violência doméstica e menosprezo ou discriminação à condição de mulher. Entretanto, todo o conjunto da estrutura social patriarcalista se encontra em desconstrução, descontruindo até mesmo o conceito de mulher e trazendo à tona todas aquelas pessoas que existiam a margem da sociedade, como os homossexuais, bissexuais e, no caso deste trabalho, as pessoas transsexuais.

Nesse sentido, o presente artigo foi redigido de forma a, em primeiro momento, abordar a evolução histórica das duas normas em estudo e, em sequência, o que seria a transexualidade e o que é um indivíduo transexual na esfera jurídica.

Em um segundo momento, versa-se sobre a (im)possibilidade de a mulher transexual ser reconhecida como sujeito passivo nos crimes de violência doméstica e do crime de feminicídio, evidenciando a mulher transsexual a fim de liquidar os preconceitos existentes entre esta e a mulher cisgênera, de forma a expor a situação de fragilidade da mulher trans.

Consequentemente, visa-se estabelecer os conceitos de gênero, papel de gênero e expressão de gênero como forma de entender que não existem diferenças entre a mulher transexual e a mulher cisgênera.

Por fim, busca-se expor como a doutrina recepciona esta temática, evidenciando assim os conceitos da doutrina mais conservadorista juntamente com os conceitos da doutrina moderna do direito penal. Usando para a confecção de tal projeto a metodologia bibliográfica 
e a analítico-dogmática. Com a metodologia bibliográfica faz-se uma análise da literatura jurídica especializada e dedicada ao tema do reconhecimento dos direitos às pessoas transexuais. A investigação analítico-dogmática tem por objetivo buscar e integrar a legislação aplicável de forma a interpretá-la para viabilizar o máximo do reconhecimento de novos direitos, uma vez que o direito é um ser em constante evolução e deve se moldar a sociedade a qual rege.

\section{DA EVOLUÇÃO HISTÓRICA DA LEI MARIA DA PENHA E DO FEMÍNICIDIO}

A estrutura da sociedade brasileira advém de uma cultura coronelista e patriarcalista, características estas que perpetuam até os dias atuais. No Brasil colônia a mulher era considerada como propriedade, primeiro, do pai e, após o casamento, do marido, tendo como funções: conceber herdeiros ao marido, e, ser a cuidadora do lar e dos filhos.

Estas características patriarcais começaram a dissipar com o surgimento do movimento feminista, tendo como marco histórico, no Brasil, a marcha das mulheres reivindicando o direito ao voto no ano de 1934, durante o governo Vargas. O sufrágio feminino permitiu que as mulheres tivessem voz onde nunca foram ouvidas, podendo agora decidir sobre seus direitos e deveres como cidadã ativa da sociedade brasileira.

Ocorre que, nesse contexto social machista, o homem podia dispor da mulher como bem entendesse, estabelecendo uma relação familiar abusiva. Nesses moldes, as relações domésticas eram repletas de agressões físicas e psicológicas para com as esposas/filhas. Outrossim, nas relações conjugais, a ocorrência de estupros era muito comum, visto que a mulher não podia negar a conjunção carnal com o marido.

Essa situação da mulher como sexo frágil e submisso ao marido se perpetua até os dias atuais, em pleno século XXI, mesmo com todos os movimentos feministas que buscam a igualdade entre os gêneros.

Culturalmente, em várias partes do mundo, a mulher é inferiorizada sob diversos prismas. Pior, quando é violentada e até mesmo morta, em razão de costumes, tradições ou regras questionáveis sob a aura dos direitos humanos fundamentais. No Brasil, verificou-se (e ainda se constata) uma subjugação da mulher no nível cultural, que resvala em costumes e tradições (NUCCI, 2019, p. 125).

A Lei Maria da Penha (Lei $\left.{ }^{\circ} 11.340 / 06\right)$, o objeto de estudo deste trabalho, foi instituída com o intuito de punir, de maneira mais abrasiva, as agressões contra a mulher no âmbito das relações domésticas e familiares. Levando este nome em homenagem a Maria da Penha Maia, que viveu anos em um relacionamento abusivo, sendo vítima, por parte de seu 
marido, de inúmeras agressões físicas e psicológicas, diversas tentativas de homicídio (afogamento e eletrocussão) até que por fim, após sofrer um atentado com arma de fogo, ficou paraplégica. O marido de Maria da Penha só foi punido depois de 19 (dezenove) anos de julgamento, ficando apenas dois anos em regime fechado (SENADO NOTÍCIAS, 2019).

\begin{abstract}
$\mathrm{Na}$ realidade, muitos maridos, companheiros, namorados matam a mulher porque se sentem mais fortes que ela, o que é objetivo, mas também porque discutiram por conta de um jantar servido fora de hora (por exemplo), ingressando o motivo fútil. É essa a lógica adotada pela Lei Maria da Penha. Pune-se a lesão corporal contra a mulher, dentro do lar, como lesão qualificada (art. 129, § 9. ${ }^{\circ}, \mathrm{CP}$ ), independentemente do motivo. Aliás, se for torpe, por exemplo, acrescenta-se a agravante (lesionou a mulher para receber o valor de um seguro qualquer, ilustrando) (NUCCI, 2019, p. 127).
\end{abstract}

Posteriormente, adveio a Lei do Feminicídio (Lei $n^{\circ}$ 13.104/15) com o objetivo de punir os homicídios qualificado em razão do sexo feminino, nesse sentindo, o Art. 121, do Código Penal de 1940, passou a vigorar com a seguinte redação:

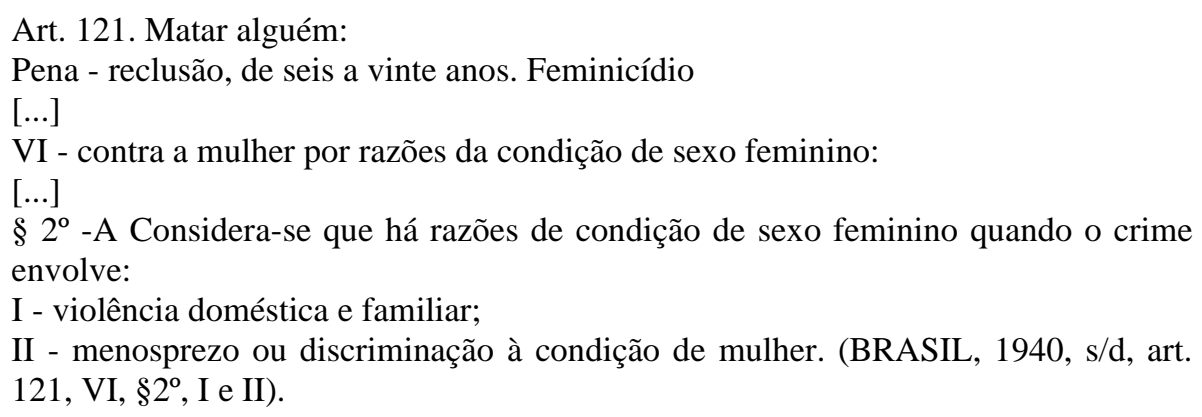

Sendo assim, é notório a estrutura machista e misógina da sociedade brasileira, uma vez que foi necessário que existissem duas leis para proteger a mulher, sendo a primeira contra as agressões dentro do âmbito doméstico, e a segunda, para proteger a vida delas. Nesse sentido, leciona Nucci:

Constitucionalmente, todos são iguais perante a lei. Essa afirmação normativa não bastava, tendo em vista que as mulheres continuavam a sofrer dentro de seus lares (principalmente) inúmeras formas de violência física e psicológica. Adveio a Lei 11.340/2006 (Lei Maria da Penha) contendo normas explicativas, programáticas e determinadas, com o fito de tutelar, de maneira mais eficiente, a condição do sexo feminino, em particular nos relacionamentos domésticos e familiares.

O feminicídio é uma continuidade dessa tutela especial, considerando homicídio qualificado e hediondo a conduta de matar a mulher, valendo-se de sua condição de sexo feminino (NUCCI, 2019, p. 125-126).

Segundo o Atlas da Violência de 2019, estudo desenvolvido pelo Instituto de Pesquisa Econômica Aplicada - IPEA, na década de 2007-2017 verificou-se um aumento expressivo de $30,7 \%$ no número de homicídios de mulheres.

A magnitude do fenômeno e de suas variações pode ser mais bem aferida em termos da taxa de homicídio por grupo de 100 mil mulheres, que permite maior comparabilidade temporal e entre as diferentes unidades federativas. Entre 2007 e 
2017 houve aumento de $20,7 \%$ na taxa nacional de homicídios de mulheres, quando a mesma passou de 3,9 para 4,7 mulheres assassinadas por grupo de 100 mil mulheres. Nesse período, houve crescimento da taxa em 17 Unidades da Federação. Já no recorte de 2012 a 2017, observamos aumento de $1,7 \%$ na taxa nacional e um aumento maior ainda de 5,4\% no último ano, período em que se verificam taxas ascendentes em 17 UFs em relação a 2016 (IPEA; FBSP, 2019, p.35).

Entretanto, esses dados são mais alarmantes quando se reduz para a raça/etnia da vítima. As mulheres negras, de acordo com o IPEA, são as maiores vítimas do feminicídio:

\begin{abstract}
Enquanto a taxa de homicídios de mulheres não negras teve crescimento de 4,5\% entre 2007 e 2017, a taxa de homicídios de mulheres negras cresceu 29,9\%. Em números absolutos a diferença é ainda mais brutal, já que entre não negras o crescimento é de $1,7 \%$ e entre mulheres negras de 60,5\%. Considerando apenas o último ano disponível, a taxa de homicídios de mulheres não negras foi de 3,2 a cada 100 mil mulheres não negras, ao passo que entre as mulheres negras a taxa foi de 5,6 para cada 100 mil mulheres neste grupo (IPEA; FBSP, 2019, p.38).
\end{abstract}

Sendo assim, pode-se aferir a partir desses dados que as políticas públicas acabam por conferir um certo empoderamento as mulheres vítimas de violência doméstica. A vítima acaba se sentindo protegida pela lei, tendo coragem de denunciar os casos de agressões domésticas, uma vez que nestes casos não se tem testemunhas, pois os envolvidos são somente os cônjuges.

Ambas as leis tutelam sobre a vida e a integridade física da mulher, tento como critério objetivo a vítima ser mulher. Nas relações homoafetivas entre duas mulheres já se está pacificado nos tribunais brasileiros que as duas leis se aplicam normalmente, visto que a vítima é mulher (no sentido biológico). Logo, é nesse ponto que o presente artigo visa discutir: e quando a vítima é uma mulher trans, estas mesmas leis são aplicadas?

\title{
3 DA TRANSEXUALIDADE
}

A transexualidade diz respeito a condição de um indivíduo cujo o gênero com o qual se identifica socialmente diverge do sexo físico biológico. Assim, para melhor compreensão do presente estudo, adota-se as conceituações de Jaqueline Gomes de Jesus:

Sexo: Classificação biológica das pessoas como machos ou fêmeas, baseada em características orgânicas como cromossomos, níveis hormonais, órgãos reprodutivos e genitais.

Gênero: Classificação pessoal e social das pessoas como homens ou mulheres. Orienta papéis e expressões de gênero. Independe do sexo.

Expressão de gênero: Forma como a pessoa se apresenta, sua aparência e seu comportamento, de acordo com expectativas sociais de aparência e comportamento de um determinado gênero. Depende da cultura em que a pessoa vive.

Identidade de gênero: Gênero com o qual uma pessoa se identifica, que pode ou não concordar com o gênero que lhe foi atribuído quando de seu nascimento. Diferente da sexualidade da pessoa. Identidade de gênero e orientação sexual são dimensões diferentes e que não se confundem. Pessoas transexuais podem ser heterossexuais, lésbicas, gays ou bissexuais, tanto quanto as pessoas cisgênero. 
Papel de gênero: Modo de agir em determinadas situações conforme o gênero atribuído, ensinado às pessoas desde o nascimento. Construção de diferenças entre homens e mulheres. É de cunho social, e não biológico.

Cisgênero: Conceito "guarda-chuva" que abrange as pessoas que se identificam com o gênero que lhes foi determinado quando de seu nascimento.

Transgênero: Conceito "guarda-chuva" que abrange o grupo diversificado de pessoas que não se identificam, em graus diferentes, com comportamentos e/ou papéis esperados do gênero que lhes foi determinado quando de seu nascimento.

$[\ldots]$

Transexual: Termo genérico que caracteriza a pessoa que não se identifica com o gênero que lhe foi atribuído quando de seu nascimento. Evite utilizar o termo isoladamente, pois soa ofensivo para pessoas transexuais, pelo fato de essa ser uma de suas características, entre outras, e não a única. Sempre se refira à pessoa como mulher transexual ou como homem transexual, de acordo com o gênero com o qual ela se identifica.

$[\ldots]$

Travesti: Pessoa que vivencia papéis de gênero feminino, mas não se reconhece como homem ou mulher, entendendo-se como integrante de um terceiro gênero ou de um não-gênero. Referir-se a ela sempre no feminino, o artigo "a" é a forma respeitosa de tratamento (JESUS, 2012, p. 13/23).

Farias e Rosenvald (2017), esclarecem que a pessoa transexual não pode ser confundida como o homossexual, o bissexual, o intersexual (também conhecido como hermafrodita) ou mesmo com o travesti. O transexual sofre com uma dicotomia físicopsíquica, possuindo um sexo físico, distinto de sua conformação sexual psicológica. Assim, o transexual tem em sua condição um fator mais psicológico do que físico. O que define se uma pessoa é "trans" ou não deriva de um fator psicológico onde ela não se identifica com o gênero imposto a ela em seu nascimento, podendo haver, ou não, subversão a sua genitália.

A transexualidade, pela ótica médica, sempre fora vista como uma patologia passível de cura. Sendo que, a única solução para a restauração dessa patologia (a cura) seria a cirurgia de redesignação sexual. A homogeneidade, universalização e força do discurso médico é tamanha que alcança, até hoje, todas as esferas do poder estatal, consolidando na patologização da identidades trans.

Como se sabe, o transexualismo sempre foi reconhecido por entidades médicas como uma patologia ou doença, pois a pessoa teria "um desvio psicológico permanente de identidade sexual, com rejeição do fenótipo e tendência à automutilação e ao autoextermínio" (Resolução 1.955/2010 do Conselho Federal de Medicina). Na linha dessa resolução do Conselho Federal de Medicina, o transexual seria uma forma de "wanna be", pois a pessoa quer ser do outro sexo, havendo choques psíquicos graves atormentando-a. A Resolução do CFM não considera ilícita a realização de cirurgias que visam à adequação do sexo, geralmente do masculino para o feminino, autorizando a sua realização em nosso país (TARTUCE, p. 182-183, 2020).

Berenice Bento e Larissa Pelúcio, esclarecem alguns elementos históricos que firmaram tal entendimento:

$\mathrm{Na}$ década de 1950 foram publicados os primeiros artigos que registraram e defenderam a especificidade do "fenômeno transexual". Mas desde o início daquela 
década o endocrinologista Harry Benjamin se dedicava a estabelecer as ocorrências que justificariam a diferenciação das pessoas transexuais em relação às homossexualidades. A relação de abjeção que as pessoas transexuais têm com as genitálias seria uma das frequências observadas nos seus discursos. Ainda que Benjamin tenha defendido a cirurgia de transgenitalização como a única alternativa terapêutica possível para as pessoas transexuais, estabelece critérios tomados por ele como científicos para que seja possível diagnosticar "o verdadeiro transexual" e assim autorizar a intervenção. Em seu livro O fenômeno transexual, publicado em 1966, ele fornece as bases para esse diagnóstico.

O critério fundamental para definir o "transexual de verdade" seria a relação de abjeção, de longa duração, com suas genitálias. Para evitar que cometam suicídio, as cirurgias deveriam ser recomendadas a partir de um rol de procedimentos arrolados por Benjamin em sua obra seminal.

Essa posição contrapunha-se à dos profissionais da psicologia, psiquiatria e psicanálise, sempre reticentes às intervenções corporais como alternativas terapêuticas. Muitos psicanalistas consideraram esse procedimento como mutilações. Benjamin, ao contrário, afirmava que para "o transexual de verdade" psicoterapias eram inúteis. Nesses casos, apenas as cirurgias poderiam representar a solução para as "enfermidades" daqueles que têm abjeção ao corpo (BENTO; PELÚCIO, p. 570-571, 2012) (grifo nosso).

Nesse mesmo viés, Berenice Bento (2008) em sua obra "O que é Transexualidade”, esclarece que a patologização e universalização andam lado a lado. Quando os principais documentos e manuais de diagnóstico de doenças, quais sejam: Manual de Diagnóstico e Estatística de Distúrbios Mentais (DSM), Classificação Internacional de Doenças (CID-10) e a State of $\mathrm{Care}^{3}$ (SOC), classificam as pessoas trans como "portadoras de um conjunto de indicadores comuns que as posicionam como transtornadas, independentes de variáveis culturais, sociais e econômicas" (BENTO, p. 98, 2008), ocorre a generalização e universalização das condições das pessoas trans. Colocando-as no mundo como seres doentes e transtornados, impedindo-os ao acesso de bens e serviços, públicos ou privados, fundamentais ao desenvolvimento da pessoa humana.

Em combate a essa universalização da pessoa trans como sendo uma pessoa doente, surgiu a teoria da Despatologização das Identidades Trans, a qual se defende retirada dos transgêneros desse diagnóstico de pessoa doente, devendo constar apenas como uma expressão da diversidade da sexualidade humana.

A transexualidade foi oficialmente retirada da Classificação Internacional de Doenças (CID), apenas em 2018 e será incorporada no CID 11, que entrará em vigor apenas em 2022, como incongruência de gênero.

À origem da homossexualidade e da transexualidade não se conhece. Aliás, nem interessa, pois, quando se buscam causas, parece que se está atrás de um remédio, de um tratamento para encontrar cura para algum mal. Tanto que a Classificação Internacional das Doenças - CID 11 retirou os transtornos de identidade de gênero

\footnotetext{
${ }^{3}$ Estado de Cuidado (tradução livre).
} 
do capítulo de doenças mentais. Passará a ser chamado de incongruência de gênero, inserido no capítulo sobre saúde sexual (DIAS, p. 630, 2021).

A teoria da Despatologização das Identidades Trans é uma realidade que passou a consolidar na jurisprudência dos tribunais superiores brasileiros. Excluindo a utilização da expressão transexualismo, que indica justamente a existência de uma patologia, mas transexualidade, que indica uma diversidade da sexualidade humana (TARTUCE, 2020).

Assim, a Despatologização das Identidades Trans teve como importante marco jurisprudencial o Recurso Especial 1.626.739/RS, julgado em maio de 2017. O Superior Tribunal de Justiça admitiu a alteração do sexo no registro civil, sem a necessidade de realização de prévia cirurgia, sendo vedada a inclusão no registro, ainda que sigilosa, da expressão transexual ou do sexo biológico:

RECURSO ESPECIAL. AÇÃO DE RETIFICAÇÃO DE REGISTRO DE NASCIMENTO PARA A TROCA DE PRENOME E DO SEXO (GÊNERO)MASCULINO PARA O FEMININO. PESSOA TRANSEXUAL. DESNECESSIDADE DE CIRURGIA DE TRANSGENITALIZAÇÃO. 1. À luz do disposto nos artigos 55, 57 e 58 da Lei6.015/73 (Lei de Registros Públicos), inferese que o princípio da imutabilidade do nome, conquanto de ordem pública, pode ser mitigado quando sobressair o interesse individual ou o benefício social da alteração, o que reclama, em todo caso, autorização judicial, devidamente motivada, após audiência do Ministério Público. 2. Nessa perspectiva, observada a necessidade de intervenção do Poder Judiciário, admite-se a mudança do nome ensejador de situação vexatória ou degradação social ao indivíduo, como ocorre com aqueles cujos prenomes são notoriamente enquadrados como pertencentes ao gênero masculino ou ao gênero feminino, mas que possuem aparência física e fenótipo comportamental em total desconformidade com o disposto no ato registral. 3. Contudo, em se tratando de pessoas transexuais, a mera alteração do prenome não alcança o escopo protetivo encartado na norma jurídica infralegal, além de descurar da imperiosa exigência de concretização do princípio constitucional da dignidade da pessoa humana, que traduz a máxima antiutilitarista segundo a qual cada ser humano deve ser compreendido como um fim em si mesmo e não como um meio para a realização de finalidades alheias ou de metas coletivas. 4 . Isso porque, se a mudança do prenome configura alteração de gênero (masculino para feminino ou vice-versa), a manutenção do sexo constante no registro civil preservará a incongruência entre os dados assentados e a identidade de gênero da pessoa, a qual continuará suscetível a toda sorte de constrangimentos na vida civil, configurando-se flagrante atentado a direito existencial inerente à personalidade. 5. Assim, a segurança jurídica pretendida com a individualização da pessoa perante a família e a sociedade - ratio essendi do registro público, norteado pelos princípios da publicidade e da veracidade registral - deve ser compatibilizada com o princípio fundamental da dignidade da pessoa humana, que constitui vetor interpretativo de toda a ordem jurídico-constitucional. 6. Nessa compreensão, o STJ, ao apreciar casos de transexuais submetidos a cirurgias de transgenitalização, já vinha permitindo a alteração do nome e do sexo/gênero no registro civil (REsp 1.008.398/SP, Rel. Ministra Nancy Andrighi, Terceira Turma,julgado em 15.10.2009, DJe 18.11.2009; e REsp 737.993/MG, Rel. Ministro João Otávio de Noronha, Quarta Turma, julgado em 10.11.2009, DJe 18.12.2009). 7. A citada jurisprudência deve evoluir para alcançar também os transexuais não operados, conferindo-se, assim, a máxima efetividade ao princípio constitucional da promoção da dignidade da pessoa humana, cláusula geral de tutela dos direitos existenciais inerentes à personalidade, a qual, hodiernamente, é concebida como 
valor fundamental do ordenamento jurídico, o que implica o dever inarredável de respeito às diferenças. 8. Tal valor (e princípio normativo) supremo envolve um complexo de direitos e deveres fundamentais de todas as dimensões que protegem o indivíduo de qualquer tratamento degradante ou desumano, garantindo-lhe condições existenciais mínimas para uma vida digna e preservando-lhe a individualidade e a autonomia contra qualquer tipo de interferência estatal ou de terceiros (eficácias vertical e horizontal dos direitos fundamentais). 9. Sob essa ótica, devem ser resguardados os direitos fundamentais das pessoas transexuais não operadas à identidade (tratamento social de acordo com sua identidade de gênero), à liberdade de desenvolvimento e de expressão da personalidade humana (sem indevida intromissão estatal), ao reconhecimento perante a lei (independentemente da realização de procedimentos médicos), à intimidade e à privacidade (proteção das escolhas de vida), à igualdade e à não discriminação(eliminação de desigualdades fáticas que venham a colocá-los em situação de inferioridade), à saúde (garantia do bem-estar biopsicofísico) e à felicidade (bem-estar geral). 10. Consequentemente, à luz dos direitos fundamentais corolários do princípio fundamental da dignidade da pessoa humana, infere-se que o direito dos transexuais à retificação do sexo no registro civil não pode ficar condicionado à exigência de realização da cirurgia de transgenitalização, para muitos inatingível do ponto de vista financeiro (como parece ser o caso em exame) ou mesmo inviável do ponto de vista médico. 11. Ademais, o chamado sexo jurídico(aquele constante no registro civil de nascimento, atribuído, na primeira infância, com base no aspecto morfológico, gonádico ou cromossômico) não pode olvidar o aspecto psicossocial defluente da identidade de gênero autodefinido por cada indivíduo, o qual, tendo em vista a ratio essendi dos registros públicos, é o critério que deve, na hipótese, reger as relações do indivíduo perante a sociedade. 12. Exegese contrária revela-se incoerente diante da consagração jurisprudencial do direito de retificação do sexo registral conferido aos transexuais operados, que, nada obstante, continuam vinculados ao sexo biológico/cromossômico repudiado. $\mathrm{Ou}$ seja, independentemente da realidade biológica, o registro civil deve retratar a identidade de gênero psicossocial da pessoa transexual, de quem não se pode exigir a cirurgia de transgenitalização para o gozo de um direito. 13. Recurso especial provido a fim de julgar integralmente procedente a pretensão deduzida na inicial, autorizando a retificação do registro civil da autora, no qual deve ser averbado, além do prenome indicado, o sexo/gênero feminino, assinalada a existência de determinação judicial, sem menção à razão ou ao conteúdo das alterações procedidas, resguardando-se a publicidade dos registros e a intimidade da autora. (STJ, Resp. 1.626.739/RS(2016/0245586-9), 4ª T., Rel. Min. Luís Felipe Salomão, j. 09/05/2017) (grifo nosso).

A travesti, por sua vez, é o indivíduo que se "traveste" e vive um papel de gênero feminino:

São travestis as pessoas que vivenciam papéis de gênero feminino, mas não se reconhecem como homens ou como mulheres, mas como membros de um terceiro gênero ou de um não gênero. É importante ressaltar que travestis, independentemente de como se reconhecem, preferem ser tratadas no feminino, considerando insultuoso serem adjetivadas no masculino: as travestis, sim; os travestis, não (JESUS, 2012, p. 09)

Entretanto, mesmo que as travestis se identifiquem como membros de um terceiro grupo, não se enquadrando no binarismo social de gênero, por se identificarem com o sexo feminino e se representarem socialmente como mulheres não há o que se falar em não 
aplicação das referidas leis a elas. Visto que, as travestis se encontram na mesma condição de mulher.

Ambas as denominações, transexualidade e travestilidade, referem-se à identidade de gênero, ou seja, é gênero com qual a pessoa se identifica na sociedade, uma vez que esta identidade de gênero é uma construção social a partir dos papeis de gênero desempenhados pelo homem e pela mulher. Outrossim, não há o que se confundir identidade de gênero com orientação sexual, esta diz respeito a afetividade do ser humano, logo, refere-se a qual sexo a pessoa se atrai afetivamente: homossexual, bissexual, heterossexual, pansexual e assexual.

Desta forma, o âmbito de discussão deste trabalho se encontra na linha tênue entre a diferença do que seria uma "mulher biológica ou cisgênero" e o que seria uma "mulher trans", e por que destas não serem diferente. Para o estudo em questão é necessário conceituar tais termos: a) mulher biológica ou cisgênero: indivíduo ao qual desde o nascimento possui o órgão genital feminino e se identifica no mundo como sendo mulher; b) mulher transexual: indivíduo ao qual nasceu com órgão genital divergente ao gênero com o qual se enxerga (apresenta em seu corpo o órgão genital masculino: pênis), entretanto, sua psiquê não o vê como homem e sim como mulher.

A doutrina mais conservadorista estabelece que mulher seria apenas aquela que biologicamente nasceu como sendo do sexo feminino, ou seja, apresenta em seu corpo a presença do órgão sexual feminino: a vagina.

O conceito de mulher/feminino é diretamente ligado a genitália do indivíduo, de forma que, anteriormente, para que uma pessoa trans realizasse a retificação do seu nome e gênero nos seus documentos civis era necessário que ela realizasse a cirurgia de redesignação sexual.

Ocorre que tal cirurgia acarreta danos graves e irreversíveis ao ser humano, e, em muitos casos, as pessoas trans não possuem a disforia genital (aversão a sua genitália). Desse modo o Conselho Nacional de Justiça - CNJ - editou o Provimento 73/2018, o qual dispensa a realização da cirurgia de redesignação sexual para que fosse realizada a retificação do nome e gênero no registro civil das pessoas transexuais.

Isso posto, era notório a invasão do Estado a individualidade e privacidade da pessoa transexual, colocando como condição para que ela pudesse realizar a retificação de seus documentos cíveis a realizar de uma cirurgia de risco. $\mathrm{O}$ direito à integridade física de toda e qualquer pessoa, e, em especial das pessoas trans, deriva dos direitos personalíssimos da dignidade da pessoa humana. Este direito traz o fundamento para a realização da cirurgia de transgenitalização, pois o corpo de outrem é algo inviolável, logo cabe apenas ao indivíduo a 
decisão de efetuar ou não a cirurgia, sendo que, para realizar a mesma a pessoa transexual deve passar por um processo meticuloso com acompanhamento médico e psicológico. Como observa Venosa apud Szaniawski (1999) que “o transexual não redesignado vive em situação de incerteza, de angústias e de conflitos, o que lhe dificulta, senão o impede, de exercer as atividades dos seres humanos".

Assim, os direitos da personalidade e a dignidade humana consistem no fundamento para o reconhecimento jurídico da cirurgia de transgenitalização, ou ainda, a retificação do registro civil sem a realização da cirurgia, como reconhecimento da liberdade e da dignidade da pessoa que, pelas suas características, escolhe voluntariamente, após acompanhamento médico e psicológico, se submeter ao procedimento em questão.

Ocorre que, na visão mais moderna, não existe esta diferença, sendo que o conceito de mulher é um construto social, e, nas palavras de Simone de Beauvoir (1980, p. 9): "Ninguém nasce mulher: torna-se mulher".

Nesta linha de raciocínio, entende-se que uma mulher transexual nada difere de uma mulher cisgênera (presença do órgão sexual feminino), posto que esta apresenta-se publicamente como sendo mulher, comporta-se como mulher, veste-se como mulher, ou seja, se vê no mundo como uma mulher, exercendo o papel de gênero feminino, e, sendo ela uma mulher, a ela é aplicável toda e qualquer lei existem em prol da mulher biológica.

Adentrando mais no campo da transexualidade, pode-se encontrar diversas formas de se expressar como mulher. O mais comum é a mulher trans que realiza tratamento hormonal a fim de adequar o seu corpo ao seu sexo psíquico, bem como realizando a cirurgia de transgenitalização, isto é, a adequação da genitália ao seu sexo psíquico (a transformação do pênis na vagina). Entretanto, em muitos casos, o indivíduo não possui a disforia com o seu órgão sexual, não fazendo uso da técnica cirúrgica, utilizando apenas da hormonização.

Ademais, outra forma de se expressar como mulher é a utilização das vestimentas femininas e a reprodução do comportamento feminino, não fazendo o uso de nenhum procedimento médico que altere o corpo do indivíduo. Nestes casos, a mulher transexual não possui qualquer disforia nem com a forma do seu corpo ou sua genitália, entretanto, se expressa e se apresenta socialmente como sendo "mulher".

O conceito de gênero de ser mulher e da edificação do que é feminino é um conceito que está em desconstrução, até mesmo na esfera das mulheres cisgêneras. Esse padrão de gênero impõe determinados comportamentos como sendo femininos ou próprios para mulher, como por exemplo: o uso de vestimentas cor de rosa; o uso de roupas consideradas como 
femininas, saias e vestidos, por exemplo; utilização de maquiagem; comportamentos mais delicados e voltados aos afazeres do lar.

Não é a presença do órgão genital que vai identificar o indivíduo como sendo mulher. A genitália identifica, exclusivamente, o sexo biológico da pessoa, isto é, macho ou fêmea. Portanto, o gênero (homem/mulher) é uma construção social que impõem ao indivíduo normas de comportamento e vestimenta: "meninos usam azul e meninas usam rosa".

\section{DA (IM)POSSIBILIDADE DA APLICAÇÃO DA LEI MARIA DA PENHA E DA QUALIFICADORA DO FEMINICÍDIO A MULHERES TRANS}

Tanto a qualificadora do feminicídio (inciso VI do art. 121, $\S 2^{\circ}$, do Código Penal) quanto a Lei Maria da Penha (Lei $\left.n^{\circ} 11.340 / 2006\right)$ exigem uma condição especial para sua incidência, a mulher figurando o polo passivo do crime: "Art. $5^{\circ}$ Para os efeitos desta Lei, configura violência doméstica e familiar contra a mulher qualquer ação ou omissão baseada no gênero que lhe cause morte, lesão, sofrimento físico, sexual ou psicológico e dano moral ou patrimonial (BRASIL, LEI No 11.340/2006, Art. $5^{\circ}$, caput).

Segundo o inciso VI do art. 121, § $2^{\circ}$, do Código Penal, existe feminicídio quando o homicídio é cometido contra a mulher em razão da condição do sexo feminino. "A incidência da qualificadora reclama situação de violência praticada contra a mulher, em contexto caracterizado por relação de poder e submissão, praticada por homem ou mulher sobre mulher em situação de vulnerabilidade" (CUNHA, 2019, p. 61).

Não obstante, a vida humana sempre foi tutelada pelo Estado, entretanto, a mulher, nas relações domésticas, acabava por figurar um lado mais frágil e vulnerável. Estes dois institutos vieram para dar uma proteção extra a vida da mulher. Desta forma, para que haja a incidência das duas normas é imprescindível que o sujeito passivo do crime seja uma mulher.

\subsection{DA DOUTRINA CONSERVADORA}

A doutrina mais conservadorista estabelece que "mulher" seria apenas aquela que biologicamente nasceu como sendo do sexo feminino, ou seja, apresenta em seu corpo a presença do órgão sexual feminino: a vagina. Entendendo que a transexual não é mulher (apenas passa a ter órgão genital de conformidade feminina), e que, portanto, descarta, para a hipótese, a proteção especial.

A doutrina aponta alguns critérios para definir o que se pode considerar mulher para os efeitos desta qualificadora: a) psicológico: o indivíduo nasce do sexo masculino, mas, psicologicamente, não aceita esta condição e se identifica com o sexo oposto. É o que move os transexuais a buscar ao procedimento de reversão genital; b) biológico: identifica-se a mulher por sua constituição genética e suas implicações 
físicas externas; c) jurídico: para este critério, é mulher quem é assim reconhecido juridicamente, ou seja, quem exibe em seu registro civil identidade do gênero feminino, ainda que não tenha nascido nesta condição, nem exiba as características próprias do sexo feminino. É o que normalmente ocorre com os transexuais, que, após a reversão, buscam também alterar seu registro civil (CUNHA, 2019, p. 66-67).

Nesse sentindo a doutrina conservadora aceita duas dessas hipóteses para que a mulher transexual adentre no polo passivo desses institutos: o critério biológico e o critério jurídico. Defendendo o critério biológico, tem-se Cezar Bitencourt:

De um modo geral, não apresentam deficiência ou deformação em seu órgão genital de origem, apenas, psicologicamente, não se aceitam, não se conformando enquanto não conseguem, cirurgicamente, a transformação sexual, isto é, transformando-se em mulher. Segundo Genival Veloso de França, "As características clínicas do transexualismo se reforçam com a evidência de uma convicção de pertencer ao sexo oposto, o que lhe faz contestar e valer essa determinação até de forma violenta e desesperada".

Por essa razão, consideramos perfeitamente possível admitir o transexual, desde que transformado cirurgicamente em mulher, como vítima da violência sexual de gênero caracterizadora da qualificadora do feminicídio, como demonstraremos adiante (BITENCOURT, 2017. Grifo nosso.)

Como defensor do critério jurídico, tem-se Greco. Esse doutrinador leciona que para a transexual feminina configure o polo passivo na qualificadora do feminicídio e assim, consequentemente, na Lei Maria da Penha, esta deve ter realizado a retificação dos seus documentos cíveis, constando nos mesmo de forma expressa que seu sexo é feminino:

Com todo respeito às posições em contrário, entendemos que o único critério que nos traduz, com a segurança necessária exigida pelo Direito, e em especial o Direito Penal, é o critério que podemos denominar jurídico. Assim, somente aquele que for portador de um registro oficial (certidão de nascimento, documento de identidade) em que figure, expressamente, o seu sexo feminino, é que poderá ser considerado sujeito passivo do feminicídio.

Aqui, pode ocorrer que a vítima tenha nascido com o sexo masculino, havendo tal fato constado expressamente de seu registro de nascimento. No entanto, posteriormente, ingressando com uma ação judicial, vê sua pretensão de mudança de sexo atendida, razão pela qual, por conta de uma determinação do Poder Judiciário, seu registro original vem a ser modificado, passando a constar, agora, como pessoa do sexo feminino. Somente a partir desse momento é que poderá, segundo nossa posição, ser considerada como sujeito passivo do feminicídio (GRECO, 2017, p. 8081).

Este pensamento fundamenta-se no princípio penal da vedação da interpretação analógica in mala partem, ou seja, a lei penal não pode ser interpretada extensivamente adotando-se lei prejudicial ao réu, reguladora de caso semelhante, em razão de omissão do legislador quanto determinada conduta.

Se a Lei Maria da Penha tem sido interpretada extensivamente para que sua rede de proteção se estenda à pessoa que, embora não seja juridicamente reconhecida como mulher, assim se identifique, devemos lembrar que a norma em estudo tem natureza penal, e a extração de seu significado deve ser balizada pela regra de que é vedada a analogia in malam partem. E, ao contrário do que ocorre com outras qualificadoras 
do homicídio em que se admite a interpretação analógica, neste caso não se utiliza a mesma fórmula, nem há espaço para interpretação extensiva, pois não é o caso de ampliar o significado de uma expressão para que se alcance o real significado da norma. Mulher, portanto, para os efeitos penais desta qualificadora, é o ser humano do gênero feminino. A simples identidade de gênero não tem relevância para que se caracterize a qualificadora (CUNHA, 2018, p. 70).

Nesse sentido, não seria possível, em se tratando de Direito Penal, que se estenda a interpretação do conceito de "mulher" para prejudicar o réu, pois se estaria estendo o que é “mulher" para que uma lei mais gravosa (Lei Maria da Penha e a Lei do Feminicídio) incida sobre o réu.

\subsection{DA DOUTRINA MODERNA}

Com já visto no tópico anterior, o conceito da identidade feminina é uma construção social, consolidando assim que não há diferenças entre a mulher cisgênero e a transexual, desta forma, ambas, por desempenharem o papel de gênero da mulher, configuram o polo mais fraco nas relações domésticas e na estrutura social patriarcalista do Brasil. Ocorre que, para que as duas normas, a Lei Maria da Penha e a qualificadora do feminicídio, incidam nos casos concretos é imprescindível que o sujeito passivo seja "mulher". Ambas as normas tutelam sobre a vida e integridade física da mulher, dessa forma o homem não pode configurar o polo passivo desta demanda.

Assim, a doutrina moderna consolida seus argumentos no critério psicológico, ou seja, na forma como o indivíduo se identifica no mundo, não sendo necessário que este tenha passado por procedimento cirúrgico ou pela retificação de seus dados na esfera civil. Visto que, como já exposto no tópico anterior, a esfera da transexualidade vai muito além da hormonização e da cirurgia de redesignação sexual, já que nem todos os transexuais possuem uma disforia com seu corpo ou sua genitália.

Portanto, o Estado obrigar alguém a proceder com tais procedimentos é, nitidamente, uma invasão aos direitos da personalidade e integridade física do indivíduo, e, desta forma, ferindo vários dos princípios masters da Carta Magna brasileira: o princípio da dignidade da pessoa humana, da liberdade, da igualdade, da isonomia, da proteção à integridade física da pessoa humana e diversos outros. Para tanto, o Direito Civil já viabiliza a proteção aos direitos da personalidade as pessoas trans, a exemplo do direito ao uso do nome social e a retificação do sexo sem que a pessoa apresente um laudo psicológico atestando sua transexualidade. 
A Constituição de 1988 causou uma grande transformação na interpretação do direito, trazendo a necessidade de releitura a partir dos princípios previstos no texto constitucional. No que diz respeito à constitucionalização do direito civil, Fiúza esclarece:

Por constitucionalização do Direito Civil deve-se entender que as normas de Direito Civil têm que ser lidas à luz dos princípios e valores consagrados na Constituição. A bem da verdade, não só as normas de Direito Civil devem receber leitura constitucionalizada, mas todas as normas do ordenamento jurídico, sejam elas de Direito Privado, sejam de Direito Público. Este é um ditame do chamado Estado Democrático de Direito, que tem na Constituição sua base hermenêutica, o que equivale a dizer que a interpretação de qualquer norma deverá buscar adequá-la aos princípios e valores constitucionais, uma vez que esses mesmos princípios e valores foram eleitos por todos nós, por meio de nossos representantes, como pilares da sociedade e, consequentemente, do Direito (FIUZA, 2016, p.72-73).

O direito à integridade física de toda e qualquer pessoa e em especial, para fins de realização da cirurgia de redesignação sexual, das pessoas trans, deriva dos direitos personalíssimos da dignidade da pessoa humana. Como observa Venosa apud Szaniawski (1999) que "o transexual não redesignado vive em situação de incerteza, de angústias e de conflitos, o que lhe dificulta, senão o impede, de exercer as atividades dos seres humanos". Assim, os direitos da personalidade e a dignidade humana consistem no fundamento para o reconhecimento jurídico da cirurgia de transgenitalização, ou ainda, a retificação do registro civil sem a realização da cirurgia, como reconhecimento da liberdade e da dignidade da pessoa que, pelas suas características, escolhe voluntariamente, após meticuloso acompanhamento médico e psicológico, se submeter ao procedimento em questão.

Se o sexo biológico e o nome podem, nesses casos, macular a dignidade humana das pessoas transexuais, a possibilidade de retificação do registro civil, seja quanto ao nome, seja a menção ao sexo, são corolários da dignidade humana. No Brasil, o direito ao livre desenvolvimento da personalidade encontra fundamento no direito à vida e à dignidade, presentes no art. $5^{\circ}$ da Constituição de 1988 (“Art. 5 - Todos são iguais perante a lei, sem distinção de qualquer natureza, garantindo-se aos brasileiros e aos estrangeiros residentes no País a inviolabilidade do direito à vida, à liberdade, à igualdade, à segurança e à propriedade, nos termos seguintes”) e no art. 21 do Código Civil (Art. 21. A vida privada da pessoa natural é inviolável, e o juiz, a requerimento do interessado, adotará as providências necessárias para impedir ou fazer cessar ato contrário a esta norma.), na medida em que um dos objetivos da proteção da intimidade é garantir ao sujeito uma esfera de liberdade, na qual as escolhas não precisam ser justificadas a ninguém e, portanto, atendam exclusivamente ao interesse do titular do direito, em prol de seu desenvolvimento e autorrealização. 
Logo, não há o que se falar na aplicação do critério biológico ou jurídico quanto a aplicação das normas estudadas pelos argumentos e fundamentos anteriormente expostos, sendo aplicável a norma apenas o critério psicológico. Nesse viés, leciona Adriana Ramos de Mello, Juíza de Direito do Estado do Rio de Janeiro:

A qualificadora do feminicídio incide quando o sujeito passivo for mulher, entendido, na minha forma de ver, de acordo com o critério psicológico, ou seja, quando a pessoa de identificar com o sexo feminino, mesmo quando não tenha nascido com o sexo biológico feminino.

Em tese, não se admite analogia em desfavor do réu. No entanto, a Lei Maria da Penha já foi aplicada a mulher transexual por decisão da $1^{\mathrm{a}}$ Vara Criminal da Comarca de Anápolis em Goiás, da lavra da Juíza Ana Claudia Veloso Magalhães (Processo n. 201103873908, TJGO).

$[\ldots]$

A mulher transexual é uma pessoa adulta que se identifica como sendo do sexo e gênero femininos, embora tenha sido geneticamente - e oficialmente, pelos pais, quando do nascimento - designada como pertencente ao sexo masculino. Portanto, em virtude da incongruência sexo versus mente (ou cérebro), uma mulher transexual reivindica o reconhecimento social e legal como mulher.

Tal quais as mulheres genéticas, as mulheres transexuais adotam nome, aparência e comportamentos femininos em razão de sua necessidade de querer e necessitar ser tratadas como quaisquer outras mulheres (MELLO, 2015).

Nesse sentindo o TJMG - Tribunal de Justiça de Minas Gerais - em 2010 julgou um habeas corpus ao qual decidiu pela aplicação da Lei Maria Penha a uma mulher trans: Para a configuração da violência doméstica não é necessário que as partes sejam
marido e mulher, nem que estejam ou tenham sido casados, já que a união estável
também se encontra sob o manto protetivo da lei. Admite-se que o sujeito ativo seja
tanto homem quanto mulher, bastando a existência de relação familiar ou de
afetividade, não importando o gênero do agressor, já que a norma visa tão-somente à
repressão e prevenção da violência doméstica contra a mulher.
Quanto ao sujeito passivo abarcado pela lei, exige-se uma qualidade especial:
ser mulher, compreendidas como tal as lésbicas, os transgêneros, as transexuais
e as travestis, que tenham identidade com o sexo feminino.
Ademais, não só as esposas, companheiras, namoradas ou amantes estão no âmbito
de abrangência do delito de violência doméstica como sujeitos passivos. Também as
filhas e netas do agressor como sua mãe, sogra, avó ou qualquer outra parente que
mantém vínculo familiar com ele podem integrar o polo passivo da ação delituosa
(TJMG - Habeas Corpus Criminal 1.0000.09.513119-9/000, Relator(a): Des.(a) Júlio
Cezar Guttierrez, $4^{a}$ CÂMARA CRIMINAL, julgamento em $24 / 02 / 2010$, publicação
da súmula em $30 / 03 / 2010$ ) (grifo nosso).

Atualmente, a discussão a respeito da aplicabilidade de ambos os institutos já se encontra pacificada nos tribunais brasileiros, o próprio CNJ - Conselho Nacional de Justiça, publicou um enunciando ratificando tal entendimento:

ENUNCIADO 46: A lei Maria da Penha se aplica às mulheres trans, independentemente de alteração registral do nome e de cirurgia de redesignação sexual, sempre que configuradas as hipóteses do artigo $5^{\circ}$, da Lei 11.340/2006 (APROVADO POR UNANIMIDADE - IX FONAVID - Natal) (CNJ, s/d, 2017). 
Entretanto, nada está legislado, é apenas uma orientação do Conselho para que os operadores do direito sigam quando se depararem com estes casos. Sendo assim, a Comissão de Constituição, Justiça e Cidadania (CCJ) aprovou, em maio de 2019, o Projeto de Lei do Senado (PLS) 191/2017, que amplia o alcance da Lei Maria da Penha e, com isso, pretende combater a violência contra pessoas que se identificam como integrantes do gênero feminino. O texto é terminativo na comissão e, se não houver recurso para análise em Plenário, segue para a Câmara dos Deputados (SENADO NOTÍCIAS, 2019).

Nesse mesmo sentido, de interpretação do conceito de gênero feminino abordado por este projeto de lei, Adriana Ramos de Mello faz uma importante colocação sobre a Lei do Feminicídio (Lei n. 13.104/2015) dentro deste aspecto da estrutura interpretativa a fim de entender ao que se refere a norma:

O Projeto que deu origem à Lei n. 13.104/2015 (PL 8.305/2014) sofreu, pouco tempo antes de ser aprovado, uma modificação: o termo "gênero" foi substituído pela expressão "condição de sexo feminino". No entanto, entendemos que esta modificação não altera a interpretação, já que a expressão "por razões da condição de sexo feminino" prende-se, da mesma forma, a razões de gênero.

Observa-se que o legislador não trouxe uma qualificadora para a morte de mulheres. Se assim fosse, teria dito: "Se o crime é cometido contra a mulher", sem utilizar a expressão "por razões da condição de sexo feminino".

Uma vez explicado que a qualificadora não se refere a uma questão de sexo (categoria que pertence à biologia), mas a uma questão de gênero (atinente à sociologia, padrões sociais do papel que cada sexo desempenha), vale trazer algumas considerações sobre o assunto (MELLO, 2015).

Portanto, o melhor critério a ser aplicado nas causas de violência doméstica e feminicídio contra as mulheres trans é o psicológico, este que leva em conta como a pessoa se identifica no mundo.

O direito não pode jamais tutelar apenas as classes de pessoas e condutas, mas sim as circunstâncias em que estão inseridos, e, da mesma forma, não pode basear-se apenas no positivismo, na leitura crua e fria da lei. Logo, deve, antes de tudo, conjuntamente, tutelar o bem-estar geral da uma nação baseando-se nas circunstâncias e condições sociais de cada época. A ordem constitucional brasileira, estampada em se artigo $5^{\circ}$, caput, confere a todos cidadãos o direito de igualdade, seja ele de tratamento perante as leis, seja ele de respeito mútuo entre todos. 
Diante de todo o exposto, resta claro que estando num estado democrático de direito, abarcado pelos princípios da igualdade, da dignidade da pessoa humana, não restam dúvidas que sim, a transexual pode ser vítima do crime de feminicídio e ser tutelada pela Lei Maria da Penha.

\section{CONCLUSÃO}

A transexualidade não é uma promiscuidade ou um distúrbio mental, trata-se de uma inconformidade de caráter íntimo de uma pessoa com seu sexo biológico (designado no nascimento) com seu sexo psicológico (identidade de gênero). A ideia de patologização das identidades trans é uma afronta direta aos direitos fundamentais devidos à pessoa humana, ocasionando inúmeros desconfortos pessoais e inclusive a negativa do acesso a bens e serviços devidos a todas as pessoas, sejam eles públicos ou privados.

Nessa perspectiva, a Despatologização das Identidades Trans vem para retirar as pessoas transgêneros desse rol de pessoas enfermas e concebê-las como uma diversificação da própria sexualidade humana. A sexualidade de uma pessoa é intrínseca a própria condição humana, podendo ser entendida também como uma parte integral da personalidade humana. $\mathrm{O}$ desenvolvimento completo de um indivíduo, tanto social quanto interpessoal, depende da satisfação de suas necessidades humanas básicas, como o desejo de contato, afeto, intimidade, prazer e amor, ou seja, de expressar seus sentimentos. É isso que difere os humanos dos animais, a racionalidade, a capacidade de expressar-se. Restringir a sexualidade de um indivíduo é restringir sua própria humanidade.

Nesse ponto, dentro da temática LGBTQIA+, deve o Poder Estatal assimilar que a violência, assédio, discriminação, exclusão, repressão e preconceitos dirigidos contra essas pessoas por causa de sua orientação sexual ou identidade de gênero, refletem diretamente em sua integridade como ser humano, enfraquecendo seu senso de autoestima e de pertencimento à sociedade, e levando muitas dessas pessoas a reprimirem suas identidades e terem vidas marcadas pelo medo e invisibilidade.

É obrigação e responsabilidade do Estado agir de forma consciente para proteger, esta comunidade de pessoas, que historicamente, vivenciou todas as formas de violações de direitos humanos imagináveis, e inimagináveis, porque são ou são percebidas como lésbicas, gays, bissexuais, transexuais, travestis, transgêneros, intersexuais, ou porque pertencem a quaisquer outros grupos sexuais marginalizados pela sociedade.

Outrossim, a ideia da identidade feminina é um construto social, no qual a sociedade impõe regras de comportamento e vestimenta que seriam "adequadas" para que uma pessoa 
do sexo feminino fosse considerada "mulher". Desta forma, a mulher trans e travestis, por se expressarem e se identificarem como a expressão do gênero feminino também se colocam no mesmo patamar da mulher cisgênera, isto é, acaba por configurar o polo mais fraco e frágil das relações familiares e sociais, levando em conta o contexto patriarcalista do Brasil.

Sendo assim, a Lei Maria da Penha e a qualificadora de feminicídio pode ser aplicada as mulheres transexuais e travestis sem óbice algum. Uma vez que, o critério principal para que estes dois institutos incidam nos casos concretos é que o sujeito passivo do crime seja mulher (expressão e papel de gênero feminino). Nestes termos, deve ser aplicado a teoria do Critério Psicológico, o qual compreende a expressão e o papel de gênero da vítima, ou seja, leva em conta como o indivíduo se identifica no mundo, neste caso, a vítima se identificando como sendo do sexo feminino as normas devem ser aplicadas ao caso, não sendo necessário para tanto a retificação dos seus documentos civis.

Ainda que a temática seja relativamente nova, ao operador do direito é de rigor enfrentá-la. O mundo moderno urge por soluções à altura de seu progresso. Ainda que não seja com ele anuente, deve, ao menos, ser compatível com o que se espera de uma ciência evolutiva. O Direito já respondeu e se adaptou com maestria à era ambiental, à era coletiva, à era digital e, hodiernamente deve encarar com ética e responsabilidade o desafio de adequação dos transexuais à sua realidade, a fim de que não remanesça sem identidade social, seja no âmbito do direito privado e, principalmente, diante do direito público, obrigação maior do Estado e objeto do presente texto, o qual teve por objetivo estimular à discussão acerca do feminicídio e a lei Maria da Penha a possibilidade da pessoa transexual figurar como vítima desse crime hediondo.

\section{REFERÊNCIAS BIBLIOGRÁFICAS}

BITENCOURT, Cezar Roberto. Qualificadora do feminicídio pode ser aplicada a transexual. In: Conjur, 15 novembro de 2017. Disponível em: <https://www.conjur.com.br/2017-nov15/cezar-bitencourt-feminicidio-aplicadotransexual>. Acesso em: 21.04.20.

BRASIL. Código Civil. LEI No 10.406, DE 10 DE JANEIRO DE 2002. Disponível <http://www.planalto.gov.br/ccivil_03/leis/ 2002/110406.htm>. Acesso em 29.04.20.

BRASIL. Código Penal. DECRETO-LEI $\mathrm{N}^{\circ}$ 2.848, DE 7 DE DEZEMBRO DE 1940. Disponível em: < http://www.planalto.gov.br/ccivil_03/decre to-lei/del2848compilado.htm>. Acesso em 20.04.20.

BRASIL, CNJ - Conselho Nacional de Justiça. ENUNCIADO 46. (APROVADO POR UNANIMIDADE - IX FONAVID - 
Natal). Disponível em: < https://www.cnj.jus.br/programas-eacoes/violencia-contra-a-mulher/forumnacional-de-juizes-de-violencia-domesticae-familiar-contra-a-mulher-

fonavid/enunciados/>. Acesso em: 29.03.20.

BRASIL. Lei Maria da Penha. LEI No 11.340, DE 7 DE AGOSTO DE 2006. Disponível em: http://www.planalto.gov.br/ccivil_03/_ato2 004-2006/2006/lei/111340.htm>. Acesso em 20.04.20.

BRASIL. Constituição da República Federativa do Brasil de 1988. Disponível em:

$<$ http://www.planalto.gov.br/ccivil_03/con stituicao/constituicaocompilado.htm>.

Acesso em 29.04.20.

BRASIL. SENADO NOTÍCIAS: AGÊNCIA SENADO. Mulheres transgênero e transexuais poderão ter proteção da Lei Maria da Penha, aprova CCJ. 2019. Disponível em: $<$ https://www12.senado.leg.br/noticias/mat erias/2019/05/22/mulheres-transgenero-etransexuais-poderao-ter-protecao-da-leimaria-da-penha-aprova-ccj>. Acesso em 25.04.20.

BEAUVOIR, Simone de. O Segundo Sexo, v.I, II. Tradução Sérgio Milliet. Rio de Janeiro: Nova Fronteira, 1980.

BENTO, Berenice. O que é Transexualidade. Brasiliense: São Paulo, 2008.

BENTO, Berenice A. de M.; PELÚCIO, Larissa. Despatologização do gênero: a politização das identidades abjetas. In: Revista de Estudos Feministas, p. 569-581, maio-agosto/2012. Disponível em: < https://doi.org/10.1590/S0104- $\underline{026 \times 2012000200017}>$. Acesso em: 19.06.2021.

CUNHA, Rogério Sanches. Manual de Direito Penal: Parte Especial (arts. 121 ao 361). Ed. 10. Salvador: JusPodivm, 2018 .

DIAS, Maria Berenice. Manual de Direito das Famílias. 14. Ed. JusPodivm: Salvador, 2020.

FARIAS, Cristiano Chaves; ROSENVALD, Nelson. Curso de Direito Civil: Parte Geral e LINDB. Ed. 15. Salvador: Editora JusPodivm, 2017.

FIUZA, César. Direito Civil [Livro Eletrônico]. Curso Completo. 2. ed. São Paulo: Revistas do Tribunais, 2016. Disponível em: $<$ https://forumninja.org/direito-civil2/livros-4/>. Acesso em: 29.04.20.

GRECO, Rogério. Curso de Direito Penal: parte especial, Volume II: Crimes Contra a Pessoa: Artigos 121 a 212 do Código Penal. 14. ed. Niterói - RJ: Editora Impetus, 2017.

IPEA - Instituto de Pesquisa Econômica Aplicada; FBSP - Fórum Brasileiro de Segurança Pública. Atlas da violência 2019. Brasília: Rio de Janeiro: São Paulo: 2019. Disponível em: < http://www.ipea.gov.br/atlasviolencia/dow nload/19/atlas-da-violencia-2019>. Acesso em 20.03.20.

JESUS, Jaqueline Gomes de. Orientações Sobre Identidade de Gênero: Conceitos e Termos. Brasília: Autor, 2012. Disponível em: < https://www.sertao.ufg.br/up/16/o/ORIEN TA\%C3\%87\%C3\%95ES_POPULA\%C3\% 
87\%C3\%83O_TRANS.pdf?1334065989>

>. Acesso em: 05.04.20.

MELLO, Adriana Ramos de. Feminicídio: Breves Comentários à Lei 13.104/15. In: Direito em Movimento, v. 23, p. 47-100, $2^{\circ}$ sem. Rio de Janeiro: 2015. Disponível em: $<$ https://www.emerj.tjrj.jus.br/revistadireit oemovimento_online/edicoes/volume23/vo lume23_49.pdf $>$. Acesso em 29.04.20.

MOTTA, Artur Francisco Mori Rodrigues. A dignidade da pessoa humana e sua definição. In: Âmbito Jurídico, Rio Grande, XVI, n. 119, dez 2013. Disponível em: <http://www.ambitojuridico.com.br/site/?n_link=revista_artigo s_leitura\&artigo_id=14054.>. Acesso em 29.04.20.

NUCCI, Guilherme de Souza. Curso de Direito Penal: parte especial: arts. 121 a
212 do Código Penal. Ed. 3. Rio de Janeiro: Forense, 2019.

TARTUCE, Flávio. Manual de Direito Civil: Volume Único. 10. Ed. Forense: Rio de Janeiro; Método: São Paulo, 2020.

\section{TJMG - Habeas Corpus Criminal} 1.0000.09.513119-9/000, Relator(a): Des.(a) Júlio Cezar Guttierrez, $4^{\text {a }}$ CÂMARA CRIMINAL, julgamento em 24/02/2010, publicação da súmula em $30 / 03 / 2010$.

VENOSA, Sílvio de Salvo. Direito Civil: Parte Geral. Ed. 13. São Paulo: Atlas, 2013. Disponível em: < https://direitouninovest.files.wordpress.co $\mathrm{m} / 2016 / 04 /$ direito-civil-vol-1-parte-geralvenosa-sc3adlvio-de-salvo-13ed-20131.pdf>. Acesso em: 29.04.20.

\section{THE (IN)APPLICABILITY OF THE QUALIFIER OF FEMINICIDE AND THE MARIA DA PENHA LAW TO TRANSSEXUAL WOMEN}

Edson Jordan Mendes de Souza | Francielle da Conceição Drumond Figueiredo

How to cite this article: SOUZA, Edson Jordan Mendes de; FIGUEIREDO, Francielle da Conceição Drumond. A (in)aplicabilidade da qualificadora do feminicídio e da Lei Maria da Penha às mulheres transexuais. Revista de Ciências do Estado. Belo Horizonte: v. 6, n. 1, 2021.

Abstract: This article aims to present, in general, the legal recognition of the possibility of the applicability of the feminicide qualifier and the Maria da Penha Law to transsexual women. The transsexuality refers to the condition of the individual whose gender identity differs from that designated at birth, and who seeks to make the transition to the opposite gender through medical intervention, with the possibility of sexual reassignment surgery, or feminization only masculinization, depending on the gender to be transitioned, through the administration of hormones. The methodologies used to develop the present work are bibliographic and analytical dogmatic. With the bibliographic methodology we have an analysis of the specialized legal literature dedicated to the theme of the recognition of the rights of transsexual people. The analytical dogmatic investigation aims to analyze the applicable legislation and to interpret it in a way that allows the maximum recognition of new rights.

Keywords: Transsexuality; Maria da Penha Law; Femicide; Applicability. 